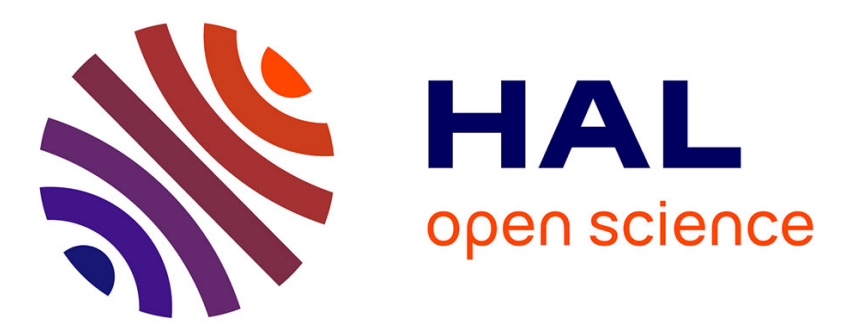

\title{
Chromium and nickel mobilization from a contaminated soil using chelants
}

Liliane Jean, François Bordas, Jean-Claude Bollinger

\section{To cite this version:}

Liliane Jean, François Bordas, Jean-Claude Bollinger. Chromium and nickel mobilization from a contaminated soil using chelants. Environmental Pollution, 2007, 147 (3), pp.729-736. hal-00638978

\section{HAL Id: hal-00638978 \\ https://hal-unilim.archives-ouvertes.fr/hal-00638978}

Submitted on 7 Nov 2011

HAL is a multi-disciplinary open access archive for the deposit and dissemination of scientific research documents, whether they are published or not. The documents may come from teaching and research institutions in France or abroad, or from public or private research centers.
L'archive ouverte pluridisciplinaire HAL, est destinée au dépôt et à la diffusion de documents scientifiques de niveau recherche, publiés ou non, émanant des établissements d'enseignement et de recherche français ou étrangers, des laboratoires publics ou privés. 


\section{using chelants}

9

10

11

Liliane Jean, François Bordas*, Jean-Claude Bollinger 


\section{Abstract}

The mobilization of chromium and nickel from an industrial soil was investigated using

3 two biodegradable chelants (citric acid and histidine), compared with a persistent one

4 (ethylenediaminetetraacetic acid). Successive metal mobilizations were carried out in batch

5 experiments. The main reactions involved were estimated by modelling the system with MINEQL+.

6 For a single mobilization, citric acid was the most effective for $\mathrm{Cr}$ mobilization and EDTA for Ni.

7 Their effectiveness could be explained by their ability to solubilize the mineral matrix and by the

8 competition for the surfaces sites to desorb $\mathrm{Cr}(\mathrm{VI})$. Before and after the mobilizations, the

9 distribution of metals was determined by a sequential extraction procedure. Only slight

10 modifications were observed due to the low percentage of solubilized metal. A concentration of

110.05 mol.L $\mathrm{L}^{-1}$ (citric acid and EDTA) allows a good compromise between metal mobilization and 12 preservation of the soil mineral integrity.

13

14 Keywords: contaminated soil, chromium, nickel, chelant, mobilization

15

16 Capsule: Chelant-induced dissolution of soil mineral matrix which controls metal solubilization 


\section{Introduction}

Metal contaminated soils are a serious environmental problem with implications for human health. The presence of metals in soil has two main origins: the alteration of the bedrock and human activities, the latter being the major cause of high levels of metals in soils (metallurgical industries, surface treatment industries, sewage sludge amendment...). The risks are related to the mobility and the bioavailability of the metals and consequently to their speciation in soil. Even when immobilized in the less mobile fractions, metals remain harmful and constitute pollutant stores, which can be removed if environmental conditions such as $\mathrm{pH}$ and Eh change (Stumm and Sulzberger, 1992; Bourg and Loch, 1995).

Various remediation methods, in-situ or ex-situ, are available. The conventional methods are solidification/stabilization, biochemical processes, phytoremediation, soil washing (Mulligan et al., 2001). Among ex-situ techniques, soil washing using chelating agents is an effective technique (Peters, 1999).

Many studies have been carried out on metal extraction with chelants such as ethylenediaminetetraacetic acid - EDTA, citric acid, nitrilotriacetic acid - NTA, [S,S]ethylenediaminedisuccinic acid - EDDS (Wasay et al., 2001; Kim et al., 2003; Tandy et al., 2004; Luo et al., 2005; Di Palma and Ferrantelli, 2005; Leštan and Kos, 2005). These chelants have a high affinity for many metals. Several parameters must be taken into account, the choice of the ratio of chelant to metals being important. Consequently, chelant concentration must be higher than trace metal concentration to obtain maximum extraction. But in the soil, there are also major elements such as Fe, Al, Mn, Mg and Ca which can be simultaneously solubilized by the chelants (Kim et al., 2003; Tandy et al., 2004).

Whereas many papers have been published about metal extraction with chelants, only few studies have been carried out about $\mathrm{Ni}$ and especially $\mathrm{Cr}$ extraction. Extractions of $\mathrm{Cr}$ and/or $\mathrm{Ni}$ using chelants were mainly studied with the purpose of phytoextraction (Turgut et al., 2004; Meers et al., 2005; do Nascimento et al., 2006). Indeed, chelating agents increase the solubility of heavy metals for plant uptake during phytoremediation (Brooks, 1998; Salt et al., 1998). It is of course important to know the degree of biodegradability of the chelants. EDTA is persistent in the environment (Bucheli-Witschel and Egli, 2001) and its presence in soil can lead to uncontrolled leaching of metals (Bordas and Bourg, 1998b), thus limiting its use for phytoextraction (Alkorta et al., 2004). Citric acid and histidine are natural organic molecules that are easily biodegradable, their half-lives, in a soil suspension, being a few days (Brynhildsen and Rosswald, 1997; Römkens et al., 2002). 
The aim of this study is to compare the ability of two natural and biodegradable chelants

\section{Materials and methods}

All reagents used to prepare the solutions were with an analytical grade. High purity deionized water (Milli-Q system: resistivity $18.2 \mathrm{M} \Omega . \mathrm{cm}, \mathrm{TOC}<10 \mu \mathrm{g} . \mathrm{L}^{-1}$ ) was used for all experiments.

\subsection{Soil sampling and characterization}

The studied soil came from a metallurgical site where special steels, superalloys, aluminium and titanium alloys are produced. The pollution was due to long time refuse storage on the bare ground. Before sampling, a superficial layer of soil $(0-5 \mathrm{~cm})$ containing refuse and the main part of the litter was discarded. The $5-10 \mathrm{~cm}$ layer of the soil was then sampled manually near the storage zone. This thickness was selected due to its contamination rate. The soil was air-dried and sieved $(<2 \mathrm{~mm})$ (AFNOR, 1994). Soil properties: $\mathrm{pH}_{\mathrm{H} 2 \mathrm{O}}(6.3 \pm 0.1), \mathrm{pH}_{\mathrm{KCl}}(5.3 \pm 0.1)$, organic carbon $\left(2.90 \pm 0.08 \mathrm{~g} \cdot \mathrm{kg}^{-1}\right)$, cation exchange capacity $(12.3 \pm 0.1 \mathrm{meq} / 100 \mathrm{~g})$ were determined by standard methods (AFNOR, 2004). The granulometry was determined by the standard method, NF X 31-107 (AFNOR, 2004). Bulk powder X-ray diffraction (XRD) was used for mineralogical

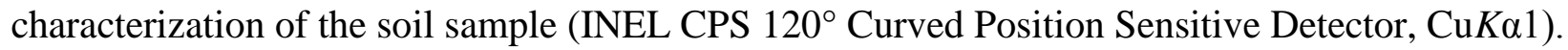

The total metal content was determined in the sample after a microwave-assisted digestion with aqua regia (microwave oven: MARCH 5, CEM). A recent study (Larner et al., 2006) proved the correctness of this method by comparison with HF digestion.

The chemical distribution of metals in the soil was quantified by the BCR sequential extractions procedure (Ure et al., 1993) accelerated by ultrasound (Pérez-Cid et al., 1998) (Table 1). The sonication was done with a $60 \mathrm{~W}$ probe (Bandelin, model HD 70). After centrifugation $(3000 \mathrm{~g}$ ), the supernatant was filtered through $0.45 \mu \mathrm{m}$ cellulose nitrate filter (Sartorius).

The fractionation of Fe was determined by oxalate (Schwertmann, 1964) and pyrophosphate extraction (McKeague, 1967). Oxalate extracts the poorly crystalline Fe oxides and the organically bound $\mathrm{Fe}$ and pyrophosphate extracts organically bound $\mathrm{Fe}$.

To determine the speciation of $\mathrm{Cr}$, an alkaline digestion was applied $\left(0.5 \mathrm{~mol} \cdot \mathrm{L}^{-1} \mathrm{NaOH}+0.28\right.$ mol. $\mathrm{L}^{-1} \mathrm{Na}_{2} \mathrm{CO}_{3}$ ) and the quantification of $\mathrm{Cr}(\mathrm{VI})$ was carried out using the colorimetric method 
with diphenylcarbazide (Centre d'expertise en analyse environnementale du Québec, 2003). Cr(III) is calculated by subtracting $\mathrm{Cr}(\mathrm{VI})$ from total $\mathrm{Cr}$.

2.2. Batch mobilization with chelating agent

Metal mobilizations were carried out in batch experiments at room temperature $\left(20 \pm 2^{\circ} \mathrm{C}\right)$.

\subsection{Respirometric tests}

for metal content. during $140 \mathrm{~h}$. The initial $\mathrm{pH}$ of the solutions was adjusted with $\mathrm{HNO}_{3}$ or $\mathrm{NaOH}$ to the soil $\mathrm{pH}_{\mathrm{H} 2 \mathrm{O}}$ value (6.3). During these experiments, no adjustment of $\mathrm{pH}$ was made; the variations were: 6.3-7.7, 6.3-6.3, 6.3-7.3 respectively for citric acid, EDTA and histidine. At the end of the experiment, after centrifugation and filtration, the soil was recovered, rinsed with $50 \mathrm{~mL}$ of de-ionized water and then air-dried at room temperature. This technique limits modifications in the metals' distribution (Bordas and Bourg, 1998a). The distribution of residual metals was determined by the sequential extractions procedure.

A respirometric BOD OxiTop® (WTW, Germany) method was used to monitor the biodegradation of citric acid. Respirometric tests were carried out in the designated measuring bottles: four replicates with citric acid solution at 0.05 mol. $\mathrm{L}^{-1}$ and two controls with de-ionized water. A ratio of $9.7 \mathrm{~g}$ of soil in $97 \mathrm{~mL}$ of solution was used. No inoculums or inhibitors were added. The suspensions of soil were stirred at $20 \pm 1{ }^{\circ} \mathrm{C}$, in a thermostated room (WTW, Germany), in the dark for 15 days. 
For all experiments, the metals were analyzed after sample centrifugation (3000 $g$ Bioblock Scientific, Sigma 2-15) and filtration ( $0.45 \mu \mathrm{m}$ cellulose nitrate filter-Sartorius). Depending on the concentration, flame atomic absorption spectrometer (Varian SpectrAA 220) or graphite furnace atomic absorption spectrometer (Varian SpectrAA 800) was used.

To estimate the main reactions involved in the extracting solutions, the system was modelled with MINEQL+, considering:

- the main solubilized elements: $\mathrm{Al}, \mathrm{Fe}, \mathrm{Mg}, \mathrm{Ca}, \mathrm{Mn}, \mathrm{Zn}, \mathrm{Cu}, \mathrm{Pb}, \mathrm{Co}, \mathrm{Cr}(\mathrm{III})$ and $\mathrm{Ni}$;

- the constants used come from MINEQL and other databases: Schecher and McAvoy (2001), Pettit and Powell (2001);

\section{Results and discussion}

\subsection{Metals speciation in the soil}

The studied soil was a sandy, acid soil, with a low organic carbon content and with moderate levels in $\mathrm{Cu}, \mathrm{Co}, \mathrm{Pb}$ (Table 2). In this study, we focused mainly on $\mathrm{Cr}$ and $\mathrm{Ni}$ because they were present in relatively large proportions, have an environmental impact and are rarely studied (especially $\mathrm{Cr}$ ) under such conditions. Table 3 shows the distribution of $\mathrm{Cr}$ and $\mathrm{Ni}$ in different soil fractions ("control"): $105 \pm 34 \%$ of total $\mathrm{Cr}$ and $87 \pm 12 \%$ of total $\mathrm{Ni}$ were recovered. $\mathrm{Cr}$ and $\mathrm{Ni}$ were present mainly in the "residual" fraction, $101 \pm 34 \%$ for $\mathrm{Cr}$ and $75 \pm 5 \%$ for $\mathrm{Ni}$. Only minor amounts of $\mathrm{Cr}$ and $\mathrm{Ni}$ were found in the "acid extractable" fraction. Although such a distribution and recovery have been observed in industrial soils (McGrath, 1996; Davidson et al., 1998), it is possible that the R2 fraction ("reducible" fraction) was under-estimated. In our studied soil, crystalline $\mathrm{Fe}\left(\mathrm{Fe}_{\mathrm{T}}-\mathrm{F}_{\text {oxa }}\right)$ is $81 \pm 2 \%$; XRD diagrams (data not shown) showed the presence of maghémite $\left(\gamma-\mathrm{Fe}_{2} \mathrm{O}_{3}\right)$. According to the literature, crystalline $\mathrm{Fe}$ is known to be only slightly solubilised by hydroxylammonium chloride (Xiao-Quan and Bin, 1993; La Force and Fendorf, 2000; Davidson et al., 2004; Neaman et al., 2004).

In the environment, chromium is present in two stable forms $\mathrm{Cr}(\mathrm{VI})$ and $\mathrm{Cr}(\mathrm{III})$. The chromium speciation experiment allows to estimate the content in $\mathrm{Cr}(\mathrm{VI})\left(28 \pm 3 \mathrm{mg} . \mathrm{kg}^{-1}\right)$ representing $25 \pm 3 \%$ of the total $\mathrm{Cr}$. 
Figure 1 indicates two steps in metal mobilization: a fast step $(<1 \mathrm{~h})$ followed by a slower one. This has already been observed by many authors (Bordas and Bourg, 1998b; Bermond et al., 2005). The fast step corresponds to the solubilization of accessible metals (exchangeable and slightly adsorbed). During this fast step, the mobilization is greater for Ni than for Cr. This result is consistent with the fractionation of the metals in the soil (Table 3) which showed more Ni in the R1 fraction (acid extractable) than Cr. The slower step may correspond to the solubilization of less mobile and less accessible metals, those bound to oxides, which requires a partial dissolution of the matrix. This step is important for the Ni extraction with EDTA, which can be explained by the amount of Ni in the "reducible fraction" fraction compared to Cr (Table 3) (Nowack, 2002; Dubbin, 11 2004).

As over a contact time of $140 \mathrm{~h}$, the major part of the mobilizable metals is extracted; this was considered to be appropriate for the present study. "True equilibrium" would be reached after longer extraction times; it depends on the chelants and the mineral matrix considered (Bordas and Bourg, 1998b; Fangueiro et al., 2002). The respirometric test (BOD OxiTop ${ }^{\circledR}$ method), showed an increase in microbial activity in the presence of citric acid after $168 \mathrm{~h}$ (data not shown), thus only a slight degradation of citric acid by microbial activity would be expected for a contact time of $140 \mathrm{~h}$. A limited and slow biodegradation of the nickel-citrate complex in the presence of a selected citrate-metabolizing bacterium has indeed been evidenced by Francis et al. (1992).

\subsection{Effect of the chelating agents on metals mobilization}

For these experiments, the initial $\mathrm{pH}$ of the chelating agent solutions was adjusted to the soil $\mathrm{pH}$ and monitored throughout the experiment. At the end of the experiments the pHs were respectively 7.7, 6.3 and 7.3 with citric acid, EDTA and histidine. The percentage of Cr extracted was calculated from total $\mathrm{Cr}$ content. The main reactions involved in the metals' complexation by chelants were estimated by modelling the system for the $\mathrm{pH}$ range 5-8 using MINEQL+ (Schecher and McAvoy, 2001).

The percentage of $\mathrm{Cr}$ and $\mathrm{Ni}$ extracted increased with the chelating agent concentration up to

31 a maximal value (Figure 2). Effectiveness of the reagents for $\mathrm{Cr}$ mobilization can be classified as:

32 citric acid > EDTA >> histidine. For 0.1 mol. $\mathrm{L}^{-1}$ citric acid, $7.7 \pm 0.1 \%$ of $\mathrm{Cr}$ was extracted, beyond

$33 \quad 0.1 \mathrm{~mol} . \mathrm{L}^{-1}$ the effectiveness of citric acid was similar. Within $\mathrm{pH}$ range of the experiments, $\mathrm{Cr}$ was 
1 totally complexed with EDTA and citrate, as $\mathrm{Cr}(\mathrm{EDTA})^{-}$and $\mathrm{Cr}$ (citrate) ${ }^{0}$ respectively. Quiros et al.

2 (1992) and Hamada et al. (2003) described only discrete Cr(citrate) ${ }_{2}{ }^{3-}$ units; these authors did not

3 quote formation constants. Thus, in the absence of data, the $\mathrm{Cr}$ (citrate) ${ }_{2}{ }^{3-}$ complex was not taken

4 into account. In the absence of data on complexation constants, the $\mathrm{Cr}$ (histidine) ${ }^{2+}$ complexes were

5 not taken into account. For Ni, a maximum of $12.8 \pm 0.8 \%$ was extracted with 0.1 mol. $\mathrm{L}^{-1}$ EDTA.

6 The effectiveness of the reagents for Ni mobilization can be classified as: EDTA > citric acid >

7 histidine. Within $\mathrm{pH}$ range of our experiments, Ni was totally complexed with chelants. Ni(EDTA) ${ }^{2-}$ and $\mathrm{Ni}$ (histidine) ${ }^{+}$were the only complexes formed with these two chelants whereas for citrate,

9 there was a mixture of three $\mathrm{Ni}$ complexes: $\mathrm{Ni}(\text { citrate })^{-}(10 \%), \mathrm{NiH}(\text { citrate })_{2}{ }^{3-}(35 \%)$ and $10 \mathrm{Ni}(\text { citrate })_{2}{ }^{4-}(55 \%)$.

11 The effectiveness of the chelants ability to solubilize $\mathrm{Cr}$ and $\mathrm{Ni}$, observed during our experiments, is not directly related to their complexation constants (Table 4). For example, Cr was better solubilized by citrate than by EDTA whereas $\log \mathrm{K}\left(\mathrm{Cr}\left(\mathrm{EDTA}^{-}\right)\right)$is greater than $\log$ $\mathrm{K}\left(\mathrm{Cr}(\text { citrate })^{0}\right)$. This order cannot be justified by the differences in $\mathrm{pH}$ conditions. For all experiments, chelants were in large excess compared to total $\mathrm{Cr}$ and $\mathrm{Ni}$. $\mathrm{Ca}, \mathrm{Fe}, \mathrm{Mn}, \mathrm{Al}$, and $\mathrm{Mg}$, were simultaneously solubilized by chelants (Table 5) corresponding to a partial dissolution of the mineral matrix. According to our modeling, the totality of the solubilized metals was complexed with chelants; however because of their excess, 70 to $80 \%$ of the chelants were always present as uncomplexed species. Consequently, the differences in the order of efficiency can not be explained totally by the chelant speciation.

For a chelant concentration of 0.05 mol. $\mathrm{L}^{-1}$, the amounts of $\mathrm{Cr}(\mathrm{III})$ and $\mathrm{Cr}(\mathrm{VI})$, present in

22 the extraction solution after $140 \mathrm{~h}$, were determined (Table 6). $\mathrm{Cr}(\mathrm{VI})$ is more mobilized in 23 presence of citric acid $(1.6 \pm 0.3 \%)$ than with EDTA $(0.6 \pm 0.1 \%)$ or histidine $(0.1 \pm 0.3 \%)$. The 24 chelating agents do not bind $\mathrm{Cr}(\mathrm{VI})$ but could desorb it by competition for surface sites as well 25 known for phosphates with ascorbate, citrate and EDTA (Nowack and Sigg, 1996; Geelhoed et al., 
1 1998; Hu et al., 2001). Then, citric acid could be more potent in desorbing Cr(VI) than EDTA or

2 histidine, in complement of the mobilization of $\mathrm{Cr}$ (III) by complexation.

3 Moreover, the mineral fraction of the soil was more solubilized with citric acid than with EDTA or histidine (Table 5) which could explain also the greater mobilization of $\mathrm{Cr}$. Then, it is possible that

$5 \mathrm{Ni}$ is included in different minerals that citric acid does not solubilize, or only slightly. The

6 effectiveness of chelants in mobilizing $\mathrm{Cr}$ and $\mathrm{Ni}$ could result of these two phenomena.

8 3.4. Successive extractions with the selected concentration

For the two most effective chelants (citric acid and EDTA), a concentration of 0.05 mol.L $\mathrm{L}^{-1}$

11 seems to be a good compromise between the mobilization of $\mathrm{Cr}$ and $\mathrm{Ni}$ and the solubilization of the

12 mineral matrix of the soil. Different authors have shown the importance of the mineral matrix.

13 Papassiopi et al. (1999) worked on a calcareous contaminated soil ( $\mathrm{Pb}, \mathrm{Zn}$ and $\mathrm{Cd}$ ) from past

14 mining and smelting activities. They showed that a limited percentage (less than 10\%) of the available EDTA was used for the removal of metals while $90 \%$ was consumed by the dissolution of calcite. This was also noted by Lim et al. (2005) who examined EDTA in the removal of metals

17 from a laboratory-contaminated soil $(\mathrm{Pb}, \mathrm{Cd}, \mathrm{Ni})$. As suggested by these authors, a low

18 concentration of chelants was favourable to the mobilization of metal while preserving the original 19 soil mineral composition.

20 A concentration of citric acid 0.05 mol.L $\mathrm{L}^{-1}$, extracted, respectively, $20.9 \pm 0.3 \% \mathrm{Co}, 2.0 \pm 0.1 \%$

$21 \mathrm{Cu}, 7.7 \pm 0.2 \% \mathrm{Zn}, 2.4 \pm 0.1 \% \mathrm{~Pb}$. At the same concentration EDTA extracted $22.0 \pm 0.4 \%, 30 \pm$ $223 \%, 6.20 \pm 0.02 \%, 27.9 \pm 0.2 \%$ of these metals. Only $\mathrm{Zn}$ is in the same proportion as $\mathrm{Cr}$ and $\mathrm{Ni}$.

23 Zn was better extracted than Cr, by citric acid and EDTA, and was solubilized in the same

24 proportion as $\mathrm{Ni}$. Taking into account their amounts in the soil, $\mathrm{Co}$ was better extracted than $\mathrm{Cu}, \mathrm{Pb}$ with citric acid; and with EDTA, they were mobilized in the same proportion. 
Successive mobilizations were carried out, during $140 \mathrm{~h}$, to check if the metals potentially

\section{(3)}

mobilizable could be solubilized, under our experimental conditions (Figure 3). Whatever the chelant considered, the percentage of $\mathrm{Cr}$ extracted during the first and the second mobilization was similar and decreased for the third. For Ni, the decrease was observed from the second mobilization on. EDTA and citrate mobilized a large amount of the major elements, hence the great mobilization of $\mathrm{Cr}$ and $\mathrm{Ni}$ in the first mobilization (Table 5). In the second and the third mobilization, major elements were mobilized at low concentrations (data not shown), which led to the decrease after these mobilizations. In the presence of chelants, the metals were extracted from a store of mobilizable metals operationally defined by the experimental conditions used. For Cr, this store is exhausted after the second extraction and for $\mathrm{Ni}$ it was exhausted after the first one.

\subsection{Distribution of metals in soil after treatment with chelating agents} after the mobilization with 0.05 mol. $\mathrm{L}^{-1}$ of chelants. After the first treatment, $\mathrm{Cr}$ and $\mathrm{Ni}$ remained mainly in the "residual" fraction (R4). The amount of $\mathrm{Ni}$ in the first three fractions $(\mathrm{R} 1+\mathrm{R} 2+\mathrm{R} 3)$ decreased from $10 \pm 1 \%$ (before treatment) to $5.1 \pm 0.8 \%$, whatever the chelant. Ni was extracted mainly from the "acid extractable" fraction (R1), as it is easily accessible to the chelating agents, but it was also extracted from the fractions R2 and R3.

In the case of $\mathrm{Cr}$, the results show that the sum of metal contained in the first three fractions $(\mathrm{R} 1+\mathrm{R} 2+\mathrm{R} 3)$ decreased slightly from $3.7 \pm 0.1 \%$ (before treatment) to $3.2 \pm 0.3 \%$, whatever the chelant. The amount of $\mathrm{Cr}$ decreased in the fraction $\mathrm{R} 3$, but increased in the fractions $\mathrm{R} 1$ and $\mathrm{R} 2$ after the treatment. It seems that $\mathrm{Cr}$ was extracted from the fractions R3 and R4 and was redistributed in both fractions, $\mathrm{R} 1$ and $\mathrm{R} 2$. In sequential extractions, the reagents used are rarely totally phase-specific. Even if the use of hydroxylammonium chloride is more generally applicable, this reagent does not bring about a complete dissolution of the iron-oxides (Xiao-Quan and Bin, 1993; La Force and Fendorf, 2000; Davidson et al., 2004; Neaman et al., 2004). During the sequential extractions, Cr bound to the iron oxides might not be extracted effectively from the 
1 fraction R2, and thus it can be extracted with the last fraction R4, but also in fraction R3. This part

2 of $\mathrm{Cr}$ can thus be redistributed in the fractions $\mathrm{R} 1$ and $\mathrm{R} 2$, during the mobilization with chelants.

In the studied case, the modifications in metal speciation from the second and the third extraction could not be evaluated because of: (i) the low quantities of extracted metals, (ii) the changes in soil composition during the extractions in presence of chelants (partial dissolution of the mineral phases), (iii) the lack of selectivity of reagents used in the sequential extractions procedure and (iv) the possible of readsorption during the protocol.

\section{Conclusions}

The results of this study, as regards the comparison between the ability of two natural and biodegradable chelants with a persistent one to solubilize chromium and nickel from a contaminated soil, can be summarized as follows:

- EDTA and citric acid appear to offer the greatest potential as chelating agents, histidine was ineffective in mobilizing $\mathrm{Cr}$ and $\mathrm{Ni}$ from the soil.

16 - Effectiveness of the chelants for Cr extraction can be classified as: citric acid > EDTA >> 17 histidine.

18 - For Ni, the effectiveness order was: EDTA $>$ citric acid $>$ histidine.

19 - The effectiveness of the chelants, to solubilize $\mathrm{Cr}$ and $\mathrm{Ni}$, observed during our experiments is not 20 directly related to their complexation constants. It could be explained by: (i) their ability to 21 solubilize the mineral matrix containing the metals ( $\mathrm{Al}, \mathrm{Ca}, \mathrm{Mn}, \mathrm{Mg}$ and $\mathrm{Fe}$ were removed simultaneously with $\mathrm{Cr}$ and $\mathrm{Ni}$ by the chelants); (ii) by the competition of the chelating agents with $\mathrm{Cr}(\mathrm{VI})$ on the surface sites.

- In the studied case, a concentration of $0.05 \mathrm{~mol} . \mathrm{L}^{-1}$ allows having a good compromise between metals mobilization and preservation the soil mineral integrity.

- After a single extraction with 0.05 mol. $\mathrm{L}^{-1}$ of chelant, a potentially remobilizable store of metals could remain available. The percentage of $\mathrm{Cr}$ extracted during the first and the second mobilizations was similar but decreased for the third. For $\mathrm{Ni}$, the decrease was observed from the second mobilization on.

- A sequential extraction procedure, carried out before and after the metal extractions showed only slight modifications due to the low percentage of solubilized metals.

\section{Acknowledgments}


1 The authors thank the anonymous reviewers for their constructive comments. This work was

2 partially supported by the Regional Council of Limousin, the "Contrat de Plan Etat-Région" and

3 "Plan Massif Central".

References

AFNOR, 1994. Qualité des sols, AFNOR Edition, Paris.

AFNOR, 2004. Evaluation de la qualité des sols, Volume 1. AFNOR Edition, Paris.

Alkorta, I., Hernández-Allica, J., Becerril, J.M., Amezaga, I., Albizu, I., Onaindia, M., Garbisu, C., 2004. Chelate-enhanced phytoremediation of soils polluted with heavy metals. Reviews in Environmental Science and Biotechnology 3, 55-70.

Bermond, A., Varrault, G., Sappin-Didier, V., Mench, M., 2005. A kinetic approach to predict soil trace metal bioavailability: preliminary results. Plant and Soil 275, 21-29.

Bordas, F., Bourg, A.C.M., 1998a. A critical evaluation of sample pretreatment for storage of contaminated sediments to be investigated for the potential mobility of their heavy metal load. Water, Air and Soil Pollution 103, 137-149.

Bordas, F., Bourg, A.C.M., 1998b. Effect of complexing agents (EDTA and ATMP) on the remobilization of heavy metals from a polluted river sediment. Aquatic Geochemistry 4, 201-214.

Bourg, A.C.M., Loch, J.P.G., 1995. Mobilization of heavy metals as affected by $\mathrm{pH}$ and by redox conditions. In: Salomons W., Stigliani W.M., Biogeodynamics of pollutants in soils and sediment. Springer, Berlin pp. 87-102.

Brooks, R.R., 1998. Plants that hyperaccumulate heavy metals, CAB International, Wallingford.

Brynhildsen, L., Rosswall, T., 1997. Effects of metals on the microbial mineralization of organic acids. Water, Air and Soil Pollution 94, 45-57. aminopolycarboxylic acids. FEMS Microbiology Reviews 25, 69-106. 
2 Centre d'expertise en analyse environnementale du Québec, 2003. Détermination du Chrome

3 hexavalent : méthode colorimétrique. MA. 200-CrHex 1.0. Ministère de l'Environnement du

4 Québec.

6 Davidson, C.M., Duncan, A.L., Littlejohn, D., Ure, A.M., Garden, L.M., 1998. A critical evaluation of the three-stage BCR sequential extraction procedure to assess the potential mobility and toxicity of heavy metals in industrially-contaminated land. Analytica Chimica Acta 363, 45-55.

10 Davidson, C.M., Hursthouse, A.S., Tognarelli, D.M., Ure, A.M., Urquhart, G.J., 2004. Should acid ammonium oxalate replace hydroxylammonium chloride in step 2 of the revised BCR sequential extraction protocol for soil and sediment? Analytica Chimica Acta 508, 193-199.

Di Palma, L., Ferrantelli, P., 2005. Copper leaching from a sandy soil: mechanism and parameters affecting EDTA extraction. Journal of Hazardous Materials B122, 85-90.

do Nascimento, C.W.A., Amarasiriwardena, D., Xing B., 2006. Comparison of natural organic acids and synthetic chelates at enhancing phytoextraction of metals from a multi-metal contaminated soil. Environmental Pollution 140, 114-123.

Dubbin, W.E., 2004. Influence of organic ligands on Cr desorption from hydroxy-Cr intercalated montmorillonite. Chemosphere 54, 1071-1077. assessment in sediments based on a kinetic approach of the EDTA extraction: search for optimal experimental conditions. Analytica Chimica Acta 459, 245-256.

Francis, A.J., Dodge, C.J., Gillow, J.B., 1992. Biodegradation of metal citrate complexes and implications for toxic-metal mobility. Nature 356, 140-142.

31 Geelhoed, J.S., Hiemstra, T., Van Riemsdijk, W.H., 1998. Competitive interaction between 
1 Hamada, Y.Z., Carlson, B.L., Shank, J.T., 2003. Potentiometric and UV-Vis spectroscopy studies of

2 citrate with the hexaquo $\mathrm{Fe}^{3+}$ and $\mathrm{Cr}^{3+}$ metal ions. Synthesis and Reactivity in Inorganic and Metal-

3 Organic Chemistry 33, 1425-1440.

Hu, H.Q., He, J.Z., Li, X.Y., Liu, F., 2001. Effect of several organic acids on phosphate adsorption by variable charge soils of central China. Environment International. 26, 353-358.

Kim, C., Lee, Y., Ong, S.K., 2003. Factors affecting EDTA extraction of lead from leadcontaminated soils. Chemosphere 51, 845-853.

11 La Force, M.J., Fendorf, S., 2000. Solid-phase iron characterization during common selective 12 sequential extractions. Soil Science Society of America Journal 64, 1608-1615.

Larner, B.L., Seen, A.J., Townsend, A.T., 2006. Comparative study of optimized BCR sequential extraction scheme and acid leaching of elements in the Certified Reference Material NIST 2711. Analytica Chimica Acta 556, 444-449.

Leštan, D., Kos, B., 2005. Soil washing using a biodegradable chelator, in: Nowack B., VanBriesen Oxford, pp. 383-397.

Lim, T.-T., Chui, P.-C., Goh, K.-H., 2005. Process evaluation for optimization of EDTA use and

Luo, C., Shen, Z., Li, X., 2005. Enhanced phytoextraction of $\mathrm{Cu}, \mathrm{Pb}, \mathrm{Zn}$ and Cd with EDTA and EDDS. Chemosphere 59, 1-11.

McGrath, D., 1996. Application of single and sequential extraction procedures to polluted and 30

31 McKeague, J.A., 1967. An evaluation of 0.1 M pyrophosphate and pyrophosphate-dithionite in comparison to oxalate as extractants of the accumulation products in podzols and some other soils. Canadian Journal of Soil Science. 47, 95-99. 
1 Meers, E., Ruttens, A., Hopgood, M.J., Samson D., Tack F.M.G., 2005. Comparison of EDTA and

2 EDDS as potential soil amendments for enhanced phytoextraction of heavy metals. Chemosphere

Mulligan, C.N., Yong, R.N., Gibbs, B.F., 2001. Remediation technologies for metal-contaminated soils and groundwater: an evaluation. Engineering Geology 60, 193-207.

Neaman, A., Waller, B., Mouele, F., Trolard, F., Bourrie, G., 2004. Improved methods for selective dissolution of manganese oxides from soils and rocks. European Journal of Soil Science 55, 47-54.

Nowack, B., 2002. Environmental chemistry of aminopolycarboxylate chelating agents.

Environmental Science and Technology 36, 4009-4016.

Nowack, B., Sigg, L., 1996. Adsorption of EDTA and metal-EDTA complexes onto goethite. Journal of Colloïd and Interface Science 177, 106-121.

Papassiopi, N., Tambouris, S., Kontopoulos, A., 1999. Removal of heavy metals from calcareous contaminated soils by EDTA leaching. Water, Air and Soil Pollution 109, 1-15.

Pérez-Cid, B., Lavilla, I., Bendicho, C., 1998. Speeding up of a three-stage sequential extraction method for metal speciation using focused ultrasound. Analytica Chimica Acta 360, 35-41.

Peters, R.W., 1999. Chelant extraction of heavy metals from contaminated soils. Journal of Hazardous Materials 66, 151-210.

Pettit, L.D., Powell, H.K.J., 2001. IUPAC stability constants database, Version 5.3. Academic Software, Otley.

Quiros, M., Goodgame, D.M.L., Williams, D.J., 1992. Crystal structure and EPR spectrum of bispyridinium bis(citrato)chromium(III) tetrahydrate. Polyhedron 11, 1343-1348.

Römkens, P., Bouwman, L., Japenga, J., Draaisma, C., 2002. Potentials and drawbacks of chelate33 enhanced phytoremediation of soils. Environmental Pollution 116, 109-121. 
1 Salt, D.E., Smith, R.D., Raskin, I., 1998. Phytoremediation. Annual Review of Plant Physiology

2 and Plant Molecular Biology 49, 643-668.

4 Schecher, W.D., McAvoy, D.C., 2001. MINEQL+: A Chemical Equilibrium Modeling System,

$5 \quad$ Version 4.5 for Windows. Environmental Research Software, Hallowell.

Schwertmann, U., 1964. Differenzierung der Eisenoxide des Bodens durch Extraktion mit Ammoniumoxalat-Lösung. Zeitschrift für Pflanzenernährung und Bodenkunde 105, 194-202.

10 Smith, R.M., Martell, A.E., 1974. Critical Stability Constants, Volume 1. Plenum Press, New-York 11 and London.

Smith, R.M., Martell, A.E., 1982. Critical Stability Constants, Volume 5. Plenum Press, New-York.

Stumm, W., Sulzberger, B., 1992. The cycling of iron in natural environments: considerations based on laboratory studies of heterogeneous redox processes. Geochimica et Cosmochimica Acta 56, 3233-3257.

Tandy, S., Bossart K,., Mueller, R., Ritschel, J., Hauser L., Schulin R., Nowack B., 2004.

Extraction of heavy metals from soils using biodegradable chelating agents. Environmental Science and Technology 38, 937-944.

Turgut, C., Pepe, M.K., Cutright, T.J., 2004. The effect of EDTA and citric acid on phytoremediation of $\mathrm{Cd}, \mathrm{Cr}$ and $\mathrm{Ni}$ from soil using Helianthus annuus. Environmental Pollution $131,147-154$.

Ure, A., Quevauviller, P., Muntau, H., Griepink, B., 1993. Improvements in the determination of extractable contents of trace metals in soil and sediment prior to certification. Commission of the European Communities, Community Bureau of Reference - BCR information, EUR 14763 EN, Brussels. polluted by heavy metals: soil flushing in columns. Water, Air and Soil Pollution 127, 301-314. 
1 Xiao-Quan, S., Bin, C., 1993. Evaluation of sequential extraction for speciation of trace metals in

2 model soil containing natural minerals and humic acid. Analytical Chemistry 65, 802-807. 
3 Table1: Sequential extractions procedure for $0.5 \mathrm{~g}$ of air-dried soil

Table2: Main physical and chemical properties of the soil

Table 3: $\mathrm{Cr}$ in the soil fractions before and after treatments with chelants

Table 4: $\mathrm{Ni}$ in the soil fractions before and after treatments with chelants

Table 5: Chelant acidity constants (pKa) and complexation constants $\left(\operatorname{LogK}_{\mathrm{ML}}\right)$ with $\mathrm{Cr}^{3+}$ and $\mathrm{Ni}^{2+}$

Table 6: Speciation of solubilized $\mathrm{Cr}$ after a single extraction $(140 \mathrm{~h})$ by the chelants (chelant concentration 0.05 mol. $\left.\mathrm{L}^{-1}\right) ; \% \mathrm{Cr}$ was based on total $\mathrm{Cr}$ content in soil

15

\section{Figure captions}

Figure 1: Extraction of $\mathrm{Cr}(\mathrm{a})$ and $\mathrm{Ni}(\mathrm{b})$ vs. contact time (chelant concentration $0.01 \mathrm{~mol} . \mathrm{L}^{-1} ; 5 \mathrm{~g}$ of soil in $50 \mathrm{~mL}$ ); \% Cr was based on total $\mathrm{Cr}$ content. Error bars represent the standard deviation of three samples.

Figure 2: $\mathrm{Cr}$ and $\mathrm{Ni}$ extracted vs. chelating agent concentration after a single extraction (\% $\mathrm{Cr}$ was based on total $\mathrm{Cr}$ content). Error bars represent the standard deviation of three samples.

Figure 3: Successive extractions of $\mathrm{Cr}$ and $\mathrm{Ni}$ (E1: first extraction, E2: second extraction, E3: third extraction); \% $\mathrm{Cr}$ was based on total $\mathrm{Cr}$ content; chelant concentrations 0.05 mol. $\mathrm{L}^{-1}$. Error bars represent the standard deviation of three samples. 
Table 1

2 Sequential extractions procedure for $0.5 \mathrm{~g}$ of air-dried soil

\begin{tabular}{|c|c|c|c|}
\hline & $\begin{array}{l}\text { Operationally defined } \\
\text { fractions }\end{array}$ & Reagents & $\begin{array}{c}\text { Time and } \\
\text { sonication power }\end{array}$ \\
\hline $\mathrm{R} 1$ & "acid extractable" & $20 \mathrm{~mL}$ AcOH 0.11 mol. $\mathrm{L}^{-1}$ & 7 min-20W \\
\hline $\mathrm{R} 2$ & "reducible" & $\begin{array}{c}20 \mathrm{~mL} \mathrm{NH}_{2} \mathrm{OH}-\mathrm{HCl} \\
0.1 \mathrm{~mol}^{-1} \mathrm{~L}^{-1} \\
\text { reagent adjusted to } \mathrm{pH}=2 \\
\text { with } \mathrm{HNO}_{3}\end{array}$ & $7 \mathrm{~min}-20 \mathrm{~W}$ \\
\hline $\mathrm{R} 3$ & "oxidizable" & $\begin{array}{c}10 \mathrm{~mL} \mathrm{H}_{2} \mathrm{O}_{2} 30 \% \\
25 \mathrm{~mL} \mathrm{AcONH} \mathrm{ANol}_{4} 1 \mathrm{~mol} \cdot \mathrm{L}^{-1} \\
\text { reagent adjusted to } \mathrm{pH}=2 \\
\text { with } \mathrm{HNO}_{3}\end{array}$ & $\begin{array}{l}2 \min -20 \mathrm{~W} \\
6 \mathrm{~min}-20 \mathrm{~W}\end{array}$ \\
\hline $\mathrm{R} 4$ & "residual" & $\begin{array}{l}7.5 \mathrm{~mL} \mathrm{HNO}_{3} 69 \%+ \\
2.5 \mathrm{~mL} \mathrm{HCl} 37 \%\end{array}$ & $\begin{array}{l}\text { microwave- } \\
\text { assisted digestion }\end{array}$ \\
\hline
\end{tabular}

3 


\section{$1 \quad$ Table 2}

2 Main physical and chemical properties of the soil

\begin{tabular}{|c|c|c|}
\hline Parameters & & Values \\
\hline Clay $(<2 \mu \mathrm{m})$ & & 177 \\
\hline Fine silt $(2 / 20 \mu \mathrm{m})$ & & 161 \\
\hline Coarse silt $(20 / 50 \mu \mathrm{m})$ & & 63 \\
\hline Fine sand $(50 / 200 \mu \mathrm{m})$ & & 119 \\
\hline Coarse sand $(200 / 2000 \mu \mathrm{m})$ & g. $\mathrm{kg}^{-1}$ & 480 \\
\hline $\mathrm{Al}$ & & $43.1 \pm 0.9$ \\
\hline $\mathrm{Fe}$ & & $33.6 \pm 0.8$ \\
\hline $\mathrm{Mg}$ & & $2.6 \pm 0.1$ \\
\hline $\mathrm{Ca}$ & & $2.2 \pm 0.1$ \\
\hline $\mathrm{Mn}$ & & $921 \pm 36$ \\
\hline $\mathrm{Zn}$ & & $138 \pm 4$ \\
\hline $\mathrm{Cu}$ & & $29 \pm 2$ \\
\hline $\mathrm{Pb}$ & mg.kg ${ }^{-1}$ & $87 \pm 3$ \\
\hline Co & & $40 \pm 2$ \\
\hline $\mathrm{Cr}$ & & $113 \pm 10$ \\
\hline $\mathrm{Ni}$ & & $280 \pm 20$ \\
\hline
\end{tabular}


$1 \quad$ Table 3

$2 \mathrm{Cr}$ and $\mathrm{Ni}$ in the soil fractions $\left(\mathrm{mg} \cdot \mathrm{kg}^{-1}\right)$ before and after treatments with chelants

\begin{tabular}{|c|c|c|c|c|c|}
\hline & \multirow{2}{*}{ Treatment extraction } & \multicolumn{4}{|l|}{ Fractions } \\
\hline & & $\mathrm{R} 1$ & $\mathrm{R} 2$ & R3 & $\mathrm{R} 4$ \\
\hline \multirow[t]{4}{*}{$\mathrm{Cr}$} & Control & $0.081 \pm 0.003$ & $0.68 \pm 0.02$ & $3.44 \pm 0.09$ & $114 \pm 39$ \\
\hline & EDTA & $0.12 \pm 0.02$ & $1.33 \pm 0.09$ & $2.01 \pm 0.32$ & $88.13 \pm 0.01$ \\
\hline & Citric acid & $0.15 \pm 0.01$ & $1.13 \pm 0.04$ & $2.04 \pm 0.33$ & $106 \pm 12$ \\
\hline & Histidine & $0.18 \pm 0.02$ & $1.24 \pm 0.10$ & $2.5 \pm 0.2$ & $96 \pm 2$ \\
\hline \multirow[t]{4}{*}{$\mathrm{Ni}$} & Control & $4.1 \pm 0.3$ & $12.6 \pm 0.4$ & $12 \pm 2$ & $201 \pm 20$ \\
\hline & EDTA & $0.8 \pm 0.2$ & $6.6 \pm 0.5$ & $8 \pm 1$ & $177 \pm 12$ \\
\hline & Citric acid & $0.78 \pm 0.01$ & $5.4 \pm 0.7$ & $5.8 \pm 0.1$ & $148 \pm 51$ \\
\hline & Histidine & $0.58 \pm 0.07$ & $4.1 \pm 0.7$ & $9 \pm 4$ & $155 \pm 64$ \\
\hline
\end{tabular}


Table 4

2 Chelant acidity constants (pKa) and complexation constants $\left(\log \mathrm{KLL}^{\mathrm{a}}\right)$ with $\mathrm{Cr}^{3+}$ and $\mathrm{Ni}^{2+}$ 3 4 5 6 7 8 9 10 11 12 13 14 15

16

17 simplification)

$18 \quad$ b from Smith and Martell, 1974, 1982;

$19{ }^{\mathbf{c}}$ from Pettit and Powell, 2001;

20

nd: no data d from Schecher and McAvoy, 2001

\begin{tabular}{|c|c|c|c|}
\hline \multirow{2}{*}{ Chelant } & \multirow{2}{*}{$\begin{array}{c}\mathrm{pKa}^{\mathrm{b}} \\
\left(\mathrm{T}=25^{\circ} \mathrm{C}, \mathrm{I}=0.1 \mathrm{M}\right)\end{array}$} & \multicolumn{2}{|c|}{$\begin{array}{c}\log K_{M L} \\
\left(\mathrm{~T}=25^{\circ} \mathrm{C}, \mathrm{I}=0.1 \mathrm{M}\right)\end{array}$} \\
\hline & & $\mathrm{Cr}^{3+}$ & $\mathrm{Ni}^{2+}$ \\
\hline EDTA & $10.17,6.11,2.68,1.5$ & $23.4^{\mathrm{c}}$ & $20.1^{\mathrm{c}}$ \\
\hline
\end{tabular}

Citric acid $\quad 5.66,4.34,2.90$

$8.7^{\mathbf{c}, \mathbf{d}}$

$6.6^{\mathrm{c}}$

Histidine

nd $16.6^{\mathrm{c}}$

${ }^{\mathrm{a}} \mathrm{K}_{\mathrm{ML}}=[\mathrm{ML}] /[\mathrm{M}] .[\mathrm{L}]$ with $\mathrm{L}=$ fully deprotonated ligand and $\mathrm{M}=$ metal cation (charges omitted for 
Table 5

2 Elements solubilized by the chelants after a single mobilization (140h) (chelant concentration 0.05

3 mol. $\left.\mathrm{L}^{-1}\right)$

\begin{tabular}{llll}
\hline \multirow{2}{*}{ Soluble metals } & \multicolumn{3}{l}{ Concentration $\left(\mu \mathrm{mol} . \mathrm{L}^{-1}\right)$} \\
\cline { 2 - 4 } & EDTA & Citric acid & Histidine \\
\hline $\mathrm{Al}$ & $7360 \pm 82$ & $10579 \pm 39$ & $82 \pm 4$ \\
$\mathrm{Fe}$ & $4570 \pm 76$ & $5850 \pm 44$ & $29 \pm 2$ \\
$\mathrm{Mg}$ & $564 \pm 7$ & $1150 \pm 13$ & $218 \pm 2$ \\
$\mathrm{Ca}$ & $4360 \pm 150$ & $3550 \pm 79$ & $788 \pm 4$ \\
$\mathrm{Mn}$ & $877 \pm 17$ & $909 \pm 12$ & $49 \pm 2$ \\
$\mathrm{Co}$ & $14.8 \pm 0.3$ & $14.1 \pm 0.2$ & $4.7 \pm 0.2$ \\
$\mathrm{Cu}$ & $14 \pm 1$ & $0.94 \pm 0.06$ & $4.9 \pm 0.9$ \\
$\mathrm{Zn}$ & $13.09 \pm 0.05$ & $16.8 \pm 0.8$ & $3.6 \pm 0.2$ \\
$\mathrm{~Pb}$ & $11.8 \pm 0.1$ & $1.01 \pm 0.05$ & $\mathrm{ND}$ \\
$\mathrm{Cr}$ & $8.5 \pm 0.3$ & $14 \pm 1$ & $1.35 \pm 0.02$ \\
$\mathrm{Ni}$ & $26 \pm 6$ & $40 \pm 5$ & $17.8 \pm 0.8$ \\
\hline
\end{tabular}

4 ND: not detected 
Table 6

2 Speciation of solubilized $\mathrm{Cr}$ after a single extraction $(140 \mathrm{~h})$ by the chelants (chelant concentration $\left.3 \quad 0.05 \mathrm{~mol} . \mathrm{L}^{-1}\right)$

\begin{tabular}{cccccc}
\hline Chelant & $\begin{array}{c}\mathrm{Cr}_{\mathrm{T}} \text { after 140 h } \\
\left(\mu \mathrm{g} . \mathrm{L}^{-1}\right)\end{array}$ & $\begin{array}{c}\mathrm{Cr}(\mathrm{VI}) \text { after } 140 \mathrm{~h} \\
\left(\mu \mathrm{g} . \mathrm{L}^{-1}\right)\end{array}$ & $\% / \mathrm{Cr}^{\mathbf{a}}$ & $\begin{array}{c}\mathrm{Cr}(\mathrm{III}) \\
\left(\mu \mathrm{g} . \mathrm{L}^{-1}\right)\end{array}$ & $\% / \mathrm{Cr}^{\mathbf{a}}$ \\
\hline Citric acid & $738 \pm 67$ & $186 \pm 40$ & $1.6 \pm 0.3$ & 552 & $4.9 \pm 0.3$ \\
EDTA & $442 \pm 16$ & $64 \pm 10$ & $0.56 \pm 0.09$ & 378 & $3.34 \pm 0.09$ \\
Histidine & $70.4 \pm 0,9$ & $15 \pm 3$ & $0.1 \pm 0.03$ & 55 & $0.49 \pm 0.03$ \\
Water & $17 \pm 1$ & $\mathrm{ND}^{\mathbf{b}}$ & - & - & - \\
\hline
\end{tabular}

4 a: \% Cr was based on total $\mathrm{Cr}$ content in soil

5 b: not detected

6 


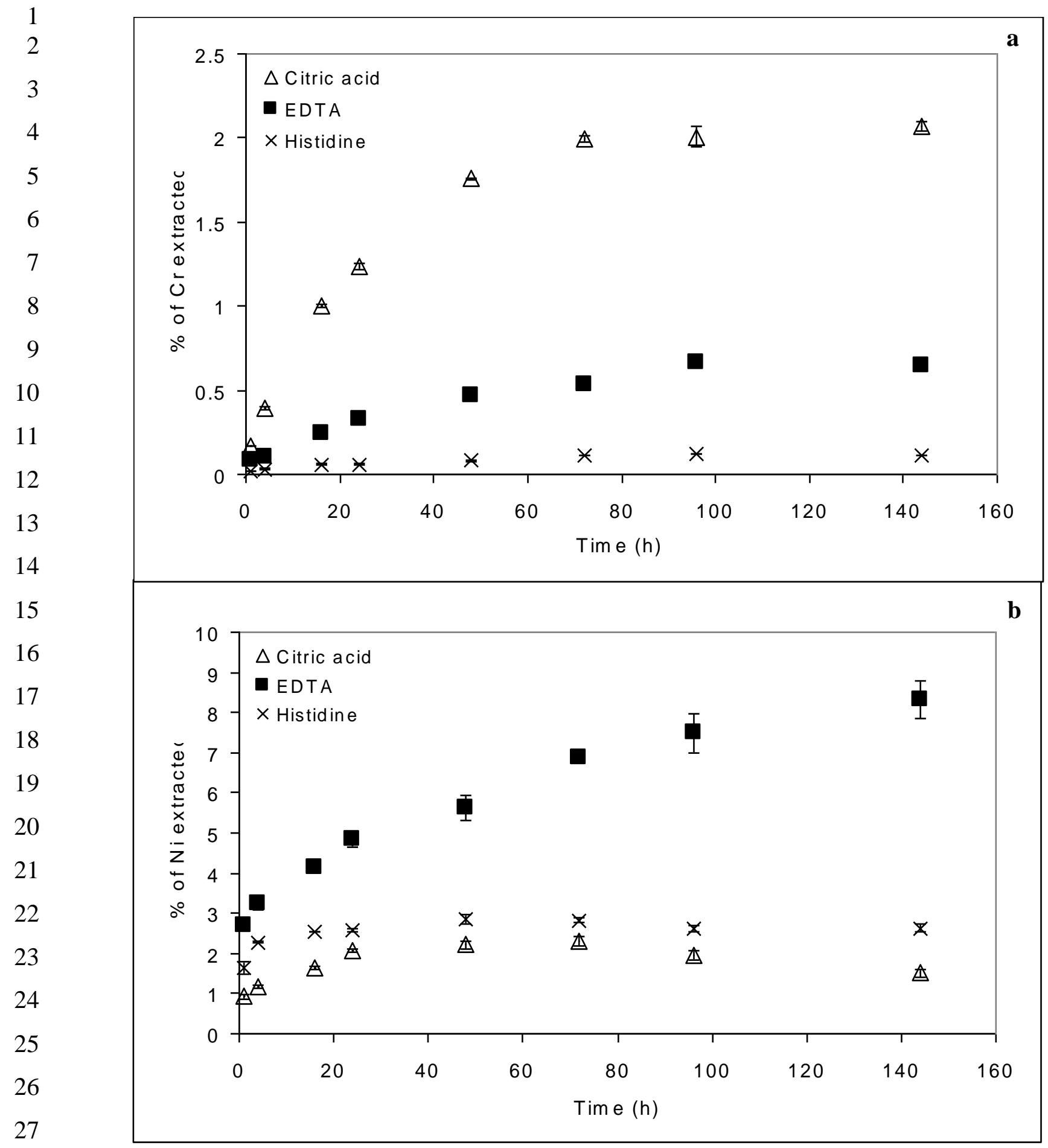

28 Fig. 1. Extraction of $\mathrm{Cr}(\mathrm{a})$ and $\mathrm{Ni}(\mathrm{b})$ vs. contact time (chelant concentration $0.01 \mathrm{mol. \textrm {L } ^ { - 1 }} ; 5 \mathrm{~g}$ of 29 soil in $50 \mathrm{~mL}$ ); \% Cr was based on total $\mathrm{Cr}$ content. Error bars represent the standard deviation of 30 three samples. 


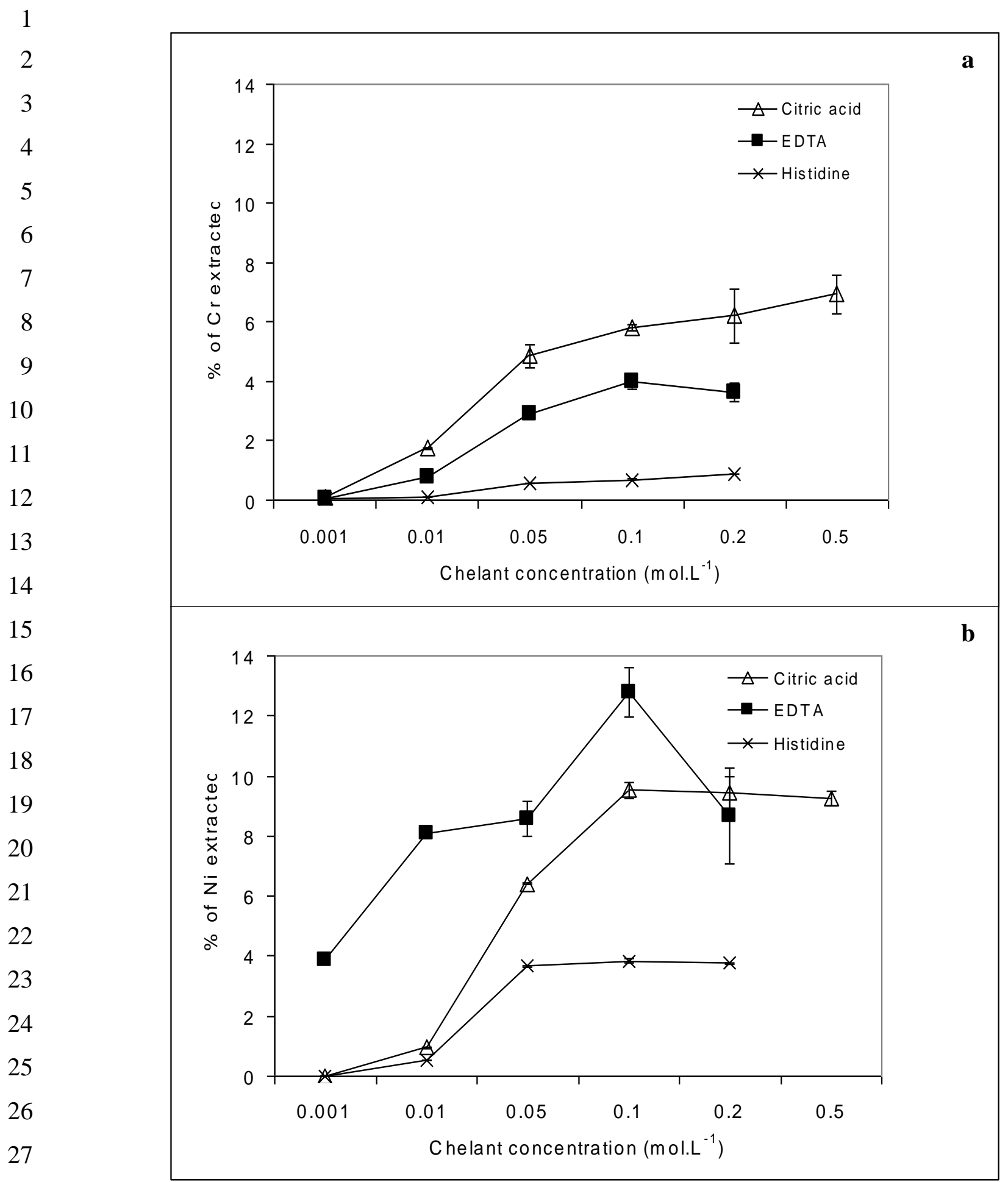

28 Fig. 2. $\mathrm{Cr}$ (a) and $\mathrm{Ni}(\mathrm{b})$ extracted vs. chelating agent concentration after a single extraction $(\% \mathrm{Cr}$

29 was based on total $\mathrm{Cr}$ content). Error bars represent the standard deviation of three samples. 


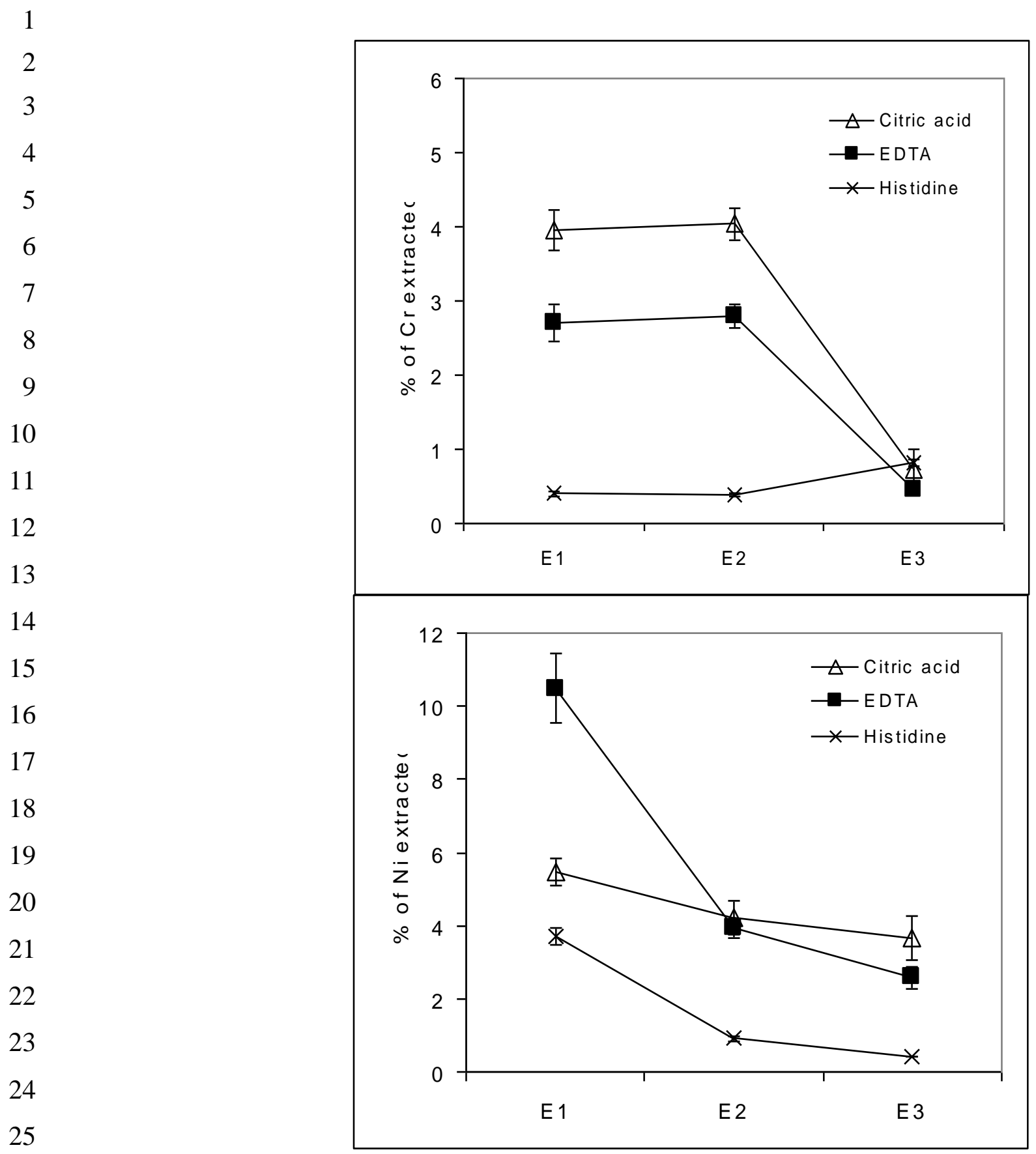

26 Fig. 3. Successive extractions of $\mathrm{Cr}$ and $\mathrm{Ni}$ (E1: first extraction, E2: second extraction, E3:

27 third extraction); \% $\mathrm{Cr}$ was based on total $\mathrm{Cr}$ content; chelant concentrations 0.05 mol.L $\mathrm{L}^{-1}$.

28 Error bars represent the standard deviation of three samples. 